\title{
Exploring expert opinion on the practicality and effectiveness of biosecurity measures on dairy farms in the United Kingdom using choice modeling
}

\author{
Orla Shortall, Martin Green, Marnie Brennan, Wendela Wapenaar, and Jasmeet Kaler ${ }^{1}$ \\ School of Veterinary Medicine and Science, University of Nottingham, Sutton Bonington Campus, Sutton Bonington, Leicestershire, LE12 5RD, \\ United Kingdom
}

\begin{abstract}
Biosecurity, defined as a series of measures aiming to stop disease-causing agents entering or leaving an area where farm animals are present, is very important for the continuing economic viability of the United Kingdom dairy sector, and for animal welfare. This study gathered expert opinion from farmers, veterinarians, consultants, academics, and government and industry representatives on the practicality and effectiveness of different biosecurity measures on dairy farms. The study used best-worst scaling, a technique that allows for greater discrimination between choices and avoids the variability in interpretation associated with other methods, such as Likert scales and ranking methods. Keeping a closed herd was rated as the most effective measure overall, and maintaining regular contact with the veterinarian was the most practical measure. Measures relating to knowledge, planning, and veterinary involvement; buying-in practices; and quarantine and treatment scored highly for effectiveness overall. Measures relating to visitors, equipment, pest control, and hygiene scored much lower for effectiveness. Overall, measures relating to direct animal-to-animal contact scored much higher for effectiveness than measures relating to indirect disease transmission. Some of the most effective measures were also rated as the least practical, such as keeping a closed herd and avoiding nose-to-nose contact between contiguous animals, suggesting that real barriers exist for farmers when implementing biosecurity measures on dairy farms. We observed heterogeneity in expert opinion on biosecurity measures; for example, veterinarians rated the effectiveness of consulting the veterinarian on biosecurity significantly more highly than dairy farmers, suggesting a greater need for veterinarians to promote their services on-farm. Still, both groups rated it as a practi-
\end{abstract}

Received May 10, 2016.

Accepted November 4, 2016.

${ }^{1}$ Corresponding author: jasmeet.kaler@nottingham.ac.uk cal measure, suggesting that the farmer-veterinarian relationship holds some advantages for the promotion of biosecurity.

Key words: biosecurity, disease control, effectiveness, practicality, best-worst scaling

\section{INTRODUCTION}

Biosecurity, defined as a series of measures aiming to stop disease-causing agents entering or leaving an area where farm animals are present (Defra, 2003), is very important for the continuing economic viability of the United Kingdom dairy sector, and for animal welfare (Defra et al., 2004). The 2004 Animal Health and Welfare Strategy for Great Britain emphasized the responsibility of animal owners in managing animal health risks and states that costs should be increasingly borne by the industry rather than by taxpayers, putting more of an onus on farmers to tackle problems (Defra et al., 2004). The strategy also stated that veterinarians are uniquely placed to promote animal health and welfare and should be at the forefront of delivering proactive disease-prevention services. In a European context, a 2013 proposal for regulation on animal health, which will be implemented after 2016, similarly states that animal owners and professionals are in the best position to manage animal health, and that veterinarians should play an active role in disease prevention and raising awareness of disease risks (European Commission, 2013).

However, consensus is lacking over which biosecurity measures are most effective for stopping the spread of disease (Valeeva et al., 2011). Several reviews have synthesized information from field trials and other types of evidence about the effectiveness of biosecurity measures or the risk of disease introduction via different pathways, which can be seen as the corollary of evaluating the effectiveness of a biosecurity measure (Wells, 2000; Cooke and Brownlow, 2011; Maunsell and Donovan, 2008; Mee et al., 2012). Several studies have focused on particular diseases or conditions (Horst et al., 1996; Sørensen et al., 2002; Valeeva et al., 2005; Garabed et al., 
2009; Gorden and Plummer, 2010; Gates et al., 2013; Kuster, 2013). However, evidence is lacking for the effectiveness of many of the biosecurity measures that are recommended on dairy farms, and some maintain that quantifying the effectiveness of a biosecurity measure based on experiments in controlled conditions is not an ideal approach to biosecurity because of the difficulty in extrapolating findings to working farms (Kuster, et al., 2015). Studies of farmers' attitudes to biosecurity have reported that the effectiveness of different measures is very important to them; farmers do not want to carry out practices that do not bring substantial benefits (Garforth et al., 2013). The practicality of measures has also been shown to be important to farmers; if the measure is effective but impractical to implement, then they are unlikely to carry it out (Kristensen and Jakobsen, 2011; Valeeva et al., 2011). However, no studies have explicitly looked into the practicality of biosecurity measures on dairy farms.

The dairy sector in the United Kingdom is the third largest milk producer in the European Union and the tenth largest in the world (Bate, 2016). Trends in the dairy sector in the United Kingdom have been in line with those of other industrialized countries, with a decreasing number of farms and increasing herd size and milk yield (AHDB Dairy, 2016). The average herd size in the United Kingdom in 2015 was 142 cows, and the average milk yield was $7,944 \mathrm{~L} /$ cow per year (AHDB Dairy, 2016). The majority of dairy farms in the United Kingdom operate a mixed grazing and housing system, with cows grazing in the summer and housed in the winter (Andersons Centre, 2013). A smaller number operate a low-input year-round grazing system, or a high-input year-round housing system. Since the 2001 foot and mouth disease outbreak, the government has been ceding control over certain areas of biosecurity to industry, as outlined in the 2004 animal health and welfare strategy (Defra, 2004). An exception is Scotland, where the government is supporting an industry-led scheme to eradicate bovine viral diarrhea (Voas, 2012).

Expert judgment is often sought in situations where problems are complex, where data are lacking, and where action is needed (Slottje et al., 2008; Martin et al., 2012). Bijker et al. (2009) state that in situations of "complex risks," the most appropriate course of action can be to try to clarify the factual base for making decisions about risk management and improve the reliability and validity of scientific knowledge by consulting with experts. A small number of expert studies have also been carried out looking into the most important or most effective biosecurity measures. Van Winden et al. (2005) undertook a systematic review of risk factors for 4 common cattle diseases and held an expert opinion workshop, asking experts to attribute a percent- age risk to each risk factor and a risk reduction factor to different biosecurity measures. Sayers et al. (2014) asked expert veterinarians and veterinary practitioners to rate the importance of several biosecurity measures on dairy farms using a Likert scale.

Several limitations have been associated with these studies. First, they focused only on asking experts to rank the effectiveness or importance of a measure without considering their relative practicality. Second, they used Likert or rating scales to gather expert opinion which have methodological deficiencies. For example, Likert scales and rating scales can involve a "scale equivalence," which means that people may interpret a rating scale differently, varying significantly across cultures (Adamsen et al., 2013). Acquiescence bias may also be present, in that people tend to respond positively to questions more often than they respond negatively (Whitty et al., 2014). Rating and Likert scales also may not discriminate sufficiently between items (Louviere et al., 2013). Methods that ask people to rank items can become too cognitively demanding and unfeasible if there are more than 7 items (Louviere et al., 2013).

A technique that overcomes these methodological deficiencies is best-worst scaling (Finn and Louviere, 1992). Best-worst scaling is a choice method that presents people with a set of options (usually 4 or 5) and asks them to pick the best and the worst (Louviere et al., 2013). This method is often used to obtain information about preferences across a large number of items, because it is not as cognitively demanding as ranking many items (Adamsen et al., 2013). It also avoids scale bias, where respondents use only part of a scale or interpret the scale in different ways (Cohen and Orme, 2004). Best-worst scaling has been used in a range of different disciplines and contexts to elicit consumer preferences in market research (Adamsen et al., 2013) and health (Lancsar and Savage, 2004), and in an agricultural context it has been used to gather expert opinion on different greenhouse gas mitigation measures on sheep farms (Jones et al., 2013) and to assess the effectiveness and practicality of measures to control Escherichia coli $\mathrm{O} 157$ on cattle farms (Cross et al., 2012).

The aim of this study was to use best-worst scaling to gather expert opinion from veterinarians (hereafter, vets), farmers, academics, consultants, and industry and government representatives on the relative practicality and effectiveness of different biosecurity measures on dairy farms in the United Kingdom. The objective was to bring greater clarity to debates in the dairy sector about what biosecurity measures farmers can and should carry out in conjunction with their vet and to contribute to debates about initiatives that could improve biosecurity in the dairy industry. 


\section{MATERIALS AND METHODS}

\section{Study Design}

Recruitment of Experts. In this study, we gathered expert opinion from veterinarians, farmers, academics, consultants, and industry and government representatives. Expertise means substantive knowledge on a particular topic that not everyone has, and an expert is someone who holds such knowledge (Martin et al., 2012). There may be different types of expertise: that which is acquired through formal training and research, and that which is based on experience (Martin et al., 2012 ) or on professional standing and performance (Burgman et al., 2006). Pearson et al. (2007) state that expertise in a health care context involves both knowledge and experience, because practitioners balance external information and their own experience when making clinical decisions. This is also true of farm animal health. Thus, the aim of the sampling process for this study was not to access a representative sample of vet, farmer, and other populations, but to use purposive sampling that aimed to access relevant expertise within these groups.

We defined expert vets as those who held a relevant postgraduate qualification: either a Royal College of Veterinary Surgeons (RCVS) certificate or a diploma in cattle health and production, or status as a fellow or honorary fellow of the RCVS, as Slottje et al. (2008) maintain that professional awards and other signs of peer recognition can be taken to denote expertise. We also stipulated that the vet must carry out all or most of their work in farm animal practice and have a minimum of 8 years' clinical experience. We defined an expert farmer as one who considered biosecurity and disease control on-farm to be a key priority and rated biosecurity on their farm as high. Expert farmers could operate different types of dairy systems (e.g., open or closed herds, zero grazing or spring/summer grazing, conventional or organic). We included farmers as experts because we determined that specially screened and selected farmers would have the experiential and knowledge-based expertise on biosecurity required to take part in the study. Expert farmers gain experience on their farm and inform themselves about biosecurity from a wide range of sources (Brennan and Christley, 2013). The inclusion of farmers as experts can be seen as analogous to the growing understanding of patients as experts on disorders they experience (Paterson and Thorne, 2000). Expert patients are considered to have experiential and knowledge-based expertise that can inform other patients, and they have day-to-day experiential expertise that clinicians do not (Hartzler and Pratt, 2011). Farmers' local expertise can also inform policy and practice in areas such as water quality protection (Oliver et al., 2012). Other experts included people from industry, academia, government, and consultancy who had substantial knowledge about and experience with biosecurity, and would be able to answer questions related to the effectiveness and practicality of biosecurity measures on farms.

We selected expert vets from lists of RCVS veterinary practitioners (RCVS, 2016) and made telephone calls with veterinary practices to verify selection criteria. We contacted expert farmers through project links with the Agriculture and Horticulture Development Board Dairy, the industry levy body, through field extension officers and through a brief questionnaire that asked farmers to rate the effectiveness of the biosecurity practices on their farm (scale of 1 to 5) and was given to farmers at 2 prominent livestock and dairy events in England in 2015. We generated a list of other academic, industry, consultant, and government biosecurity experts from literature searches and prior knowledge of expertise from published work. We contacted all selected experts by email with information and a link to the survey in May 2015. We sent a reminder email if the person did not fill out the survey.

Survey Design. To develop the list of biosecurity measures used in the survey, we compiled an initial list of 72 measures from published biosecurity guidelines and advice to farmers. We then narrowed this list down to 30 measures that were deemed to be the most important, based on reviews of the literature. We then consulted 3 expert vets at the School of Veterinary Medicine and Science, University of Nottingham, about the comprehensiveness and the wording of the list. We piloted the survey with a group of 8 expert vets. The list of 30 measures used in the study can be seen in Table 1.

For the purposes of the study, we defined biosecurity as both bioexclusion (preventing the introduction of disease-causing agents onto the farm) and biocontainment (stopping the spread of disease-causing agents to other parts of the farm and off the farm). We defined the effectiveness of a measure as how well it prevented disease-causing agents from entering or leaving any place where farm animals are present. We defined the practicality of a measure as the ease with which the measure could be implemented by the farmer. This could involve issues of physical, financial, and cultural feasibility, among other considerations.

The survey was designed and uploaded as a web survey using Sawtooth Software SSI Web 8.3.13 (Sawtooth Software, 2014). We selected optimal survey designs based on the following criteria: frequency balance, so that each item (biosecurity measure) appeared an equal number of times; orthogonality, meaning that items were paired an equal number of times; connectivity, 
Table 1. Biosecurity measures used in the study

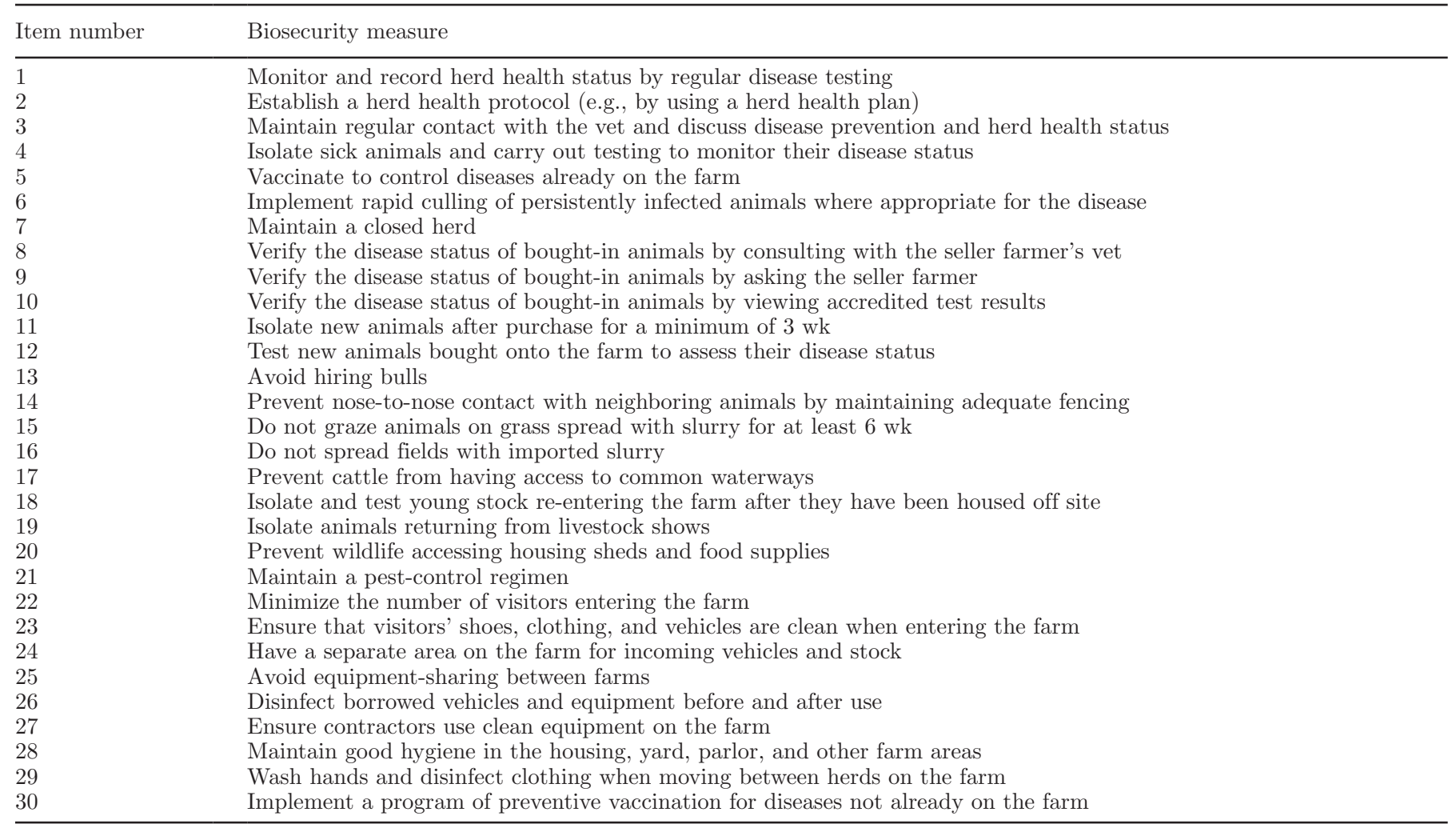

meaning that pairs were designed so that all items are connected; and positional balance, so that items were presented an equal number of times in different positions (Erdem et al., 2012). The biosecurity best-worst scaling survey consisted of 25 effectiveness questions asking the respondent to pick the most and least effective from a set of 5 biosecurity measures, and 25 practicality questions asking the respondent to pick the most and least practical from a set of 5 biosecurity measures. An example of a best-worst scaling question used in the survey can be seen in Table 2 .

We collected basic demographic information. Farmers were asked how many milking cows were in their herd; their age; what region of the United Kingdom their farm was in; whether their buying practices could be classed as open, open with biosecurity practices, or closed; whether they practiced year-round housing, seasonal grazing and housing, or year-round grazing; and how effective the disease-control measures were on their farm. Vets were asked what year they qualified as a vet; what region of the country they practiced in; what proportion of their time was spent on dairy farm work; and what percentage of that time was spent in a disease-prevention advisory role. Other experts were asked about the nature of their employment and the nature of their expertise in relation to disease control on dairy farms.

\section{Analysis}

We carried out data analysis using a multinomial logit model in a hierarchical Bayes framework, which is based on random utility theory. Random utility theory is the framework that underlies most discrete choice

Table 2. Sample best-worst scaling: Please pick the most effective and the least effective measure for stopping the spread of disease onto and within the farm, in the absence of any practical constraints to implementing them

\begin{tabular}{cll}
\hline Most effective & & Least effective \\
\hline$\square$ & Ensure that visitors' shoes, clothing, and vehicles are clean when entering the farm & $\square$ \\
$\square$ & Avoid equipment-sharing between farms & $\square$ \\
$\square$ & Maintain a closed herd & $\square$ \\
$\square$ & Monitor and record herd health status by regular disease testing & $\square$ \\
$\square$ & Minimize the number of visitors entering the farm & $\square$ \\
\hline
\end{tabular}


experiments and assumes that a person's relative preference for item A over item B is revealed in how often they choose item A over item B (Thurstone, 1927). It assumes an underlying subjective scale behind people's choices, and the utility for each item is a measure of the item's location on that scale (Louviere et al., 2013). We can express the utility of item $i$ as $U_{i}=V_{i}+\varepsilon_{i}$. Here, the utility for item $i\left(U_{i}\right)$ is made up of the explainable, systematic component $V_{i}$ and the stochastic, unexplainable component $\varepsilon_{i}$.

If we assume that the unexplainable component $\varepsilon_{i}$ follows a Gumbel distribution, then this creates a multinomial logit model that can be used to estimate the probability of each individual choosing any item as best. In this model, the probability $(P)$ that the individual chooses the ith item as best (or in this study, the most effective or most practical) from a set of $K$ items can be expressed as

$$
P_{i}=\frac{e^{U i}}{\sum e^{U K}}
$$

where $e^{U i}$ is the antilog of the utility for item $i$, and $e^{U K}$ is the antilog of the utility scores for each item in the set of $K$ items.

The probability of choosing the $j$ th item as worst (or least effective or least practical) in a set of $K$ items can be expressed as

$$
P_{j}=\frac{e^{-U j}}{\sum e^{-U K}}
$$

where $e^{-U j}$ is the antilog of the negative utility for item $j$, and $e^{-U K}$ is the antilog of the utility scores for each item in the set of $K$ items.

The probability that a person will choose the pair $i$ and $j$ as best and worst, respectively, is the probability that the difference in utility between $i$ and $j$ is greater than the difference in utility between any other pair in the set of $K$ items. This probability $(P)$ can be expressed in conditional logit form ( $i$ is chosen best and $j$ is chosen worst) as follows:

$$
P=\frac{e^{U i-U j}}{\sum_{b=1}^{K} \Sigma_{w=1}^{K} e^{U b-U w}-K},
$$

where $b$ is the best choice and $w$ is the worst choice.

For more about the multinomial logit model and hierarchical Bayesian analysis see (Mcfadden, 1980; Flynn et al., 2008; Sawtooth Software, 2009a,b,c,d). We also calculated a fit statistic that shows the internal consis- tency of each respondent's answers. Sawtooth software calculates each respondent's fit statistic as the root likelihood, based on the likelihood that they will pick each of the answers they did, given their other answers (Sawtooth Software, 2014). A minimum fit statistic is calculated as $1 / c$, where $c$ is the number of items per set. In a study asking respondents to pick from a set of 5 choices, a random set of scores would predict the respondent's answer correctly $20 \%$ of the time, generating a fit statistic of 0.20 . A minimum fit statistic of 0.2 was stipulated in this study, because each question had 5 options to choose from. All respondents' fit statistics in this study exceeded the minimum suggested, so all responses were retained. We ran the model for 20,000 "burn-in" iterations, followed by 10,000 more iterations, which were then saved and averaged to produce the scores for each measure.

We compared the practicality and effectiveness scores for a single measure using a $t$-test, and we used a Mann-Whitney U-test (Petrie and Watson, 2013) to investigate whether effectiveness was scored differently from practicality.

To explore the heterogeneity or degree of agreement and disagreement among experts for the set of measures, we computed estimate scores distributions with a mean for each respondent for each measure drawn from best-worst choices (Cross et al., 2012). Then, for each measure, we calculated a coefficient of variation and considered any values above 1 to indicate heterogeneity (Adamsen et al., 2013). For measures exhibiting heterogeneity, we conducted post hoc comparisons (using ANOVA and a Tukey honest significant difference post hoc test, or a nonparametric Kruskal-Wallis test and Dunn-Bonferroni post hoc test, depending on the distribution of the data) between expert groups' scores to see if significant differences existed between them.

We obtained ethical approval for the study from the School of Veterinary Medicine and Science, University of Nottingham (UK).

\section{RESULTS}

\section{Response Rate}

We invited a total of 84 expert vets; of these, 28 completed the survey and 8 partially completed the survey, giving a usable response rate of $33 \%$. We contacted a total of 36 other experts, of these, 16 completed the survey and 3 partially completed the survey, giving a usable response rate of $44 \%$. We contacted a total of 62 farmers; of these, 16 completed the survey and 3 partially completed the survey, giving a usable, response rate of $26 \%$. Descriptive statistics of the respondents 
Table 3. Descriptive statistics for respondents

\begin{tabular}{|c|c|c|c|}
\hline $\begin{array}{l}\text { Respondent } \\
\text { group }\end{array}$ & $\begin{array}{l}\text { Total } \\
\text { number }\end{array}$ & $\begin{array}{l}\text { Breakdown by region (no.) } \\
\text { or profession (no.) }\end{array}$ & Other statistics \\
\hline Farmer & 16 & $\begin{array}{l}\text { England northeast }=1 ; \text { England northwest } \\
=3 ; \text { England central }=4 ; \text { England } \\
\text { southeast }=4 ; \text { England southwest }=2 ; \\
\text { Northern Ireland }=0 ; \text { Scotland }=1 ; \text { Wales } \\
=1\end{array}$ & $\begin{array}{l}\text { Age (no.) } \\
\text { Under } 30 \text { yr (2) } \\
30-40 \text { yr (1) } \\
40-50 \text { yr (4) } \\
50-60 \text { yr (6) } \\
>60 \text { yr (3) } \\
\text { Herd type (no.) } \\
\text { Closed herd (11) } \\
\text { Open herd with biosecurity measures (5) } \\
\text { Housing (no.) } \\
\text { Year-round housing (2) } \\
\text { Seasonal housing and grazing (12) } \\
\text { Year-round grazing (2) }\end{array}$ \\
\hline Veterinarian & 28 & $\begin{array}{l}\text { England northeast }=2 ; \text { England northwest } \\
=8 ; \text { England central }=2 ; \text { England } \\
\text { southeast }=2 ; \text { England southwest }=10 ; \\
\text { Northern Ireland }=0 ; \text { Scotland }=2 ; \text { Wales } \\
=2\end{array}$ & $\begin{array}{l}\text { Time practicing as a veterinarian } \\
\text { Median }=19 \text { yr } \\
\text { Interquartile range }=13-30 \mathrm{yr} \\
\text { Time spent on dairy veterinary work } \\
\text { Median }=85 \% \\
\text { Interquartile range }=79-90 \% \\
\text { Time spent on dairy farms in disease-prevention advisory } \\
\text { role } \\
\text { Median }=25 \% \\
\text { Interquartile range }=20-40 \%\end{array}$ \\
\hline Other & 16 & $\begin{array}{l}\text { Industry }=7 ; \text { qualified veterinary surgeon } \\
=8 ; \text { academia }=3 ; \text { government }=4 ; \\
\text { consultancy }=5 ; \text { other }=1 \text { (dairy farmer })\end{array}$ & - \\
\hline
\end{tabular}

are shown in Table 3. All respondent's fit statistics in this study exceeded the minimum, so all responses were retained.

\section{Best-Worst Scaling Scores}

The estimated mean effectiveness and practicality scores for each measure from choice modeling are shown in Table 4. For the purposes of analysis, the different measures were grouped into sets relating to knowledge, planning and vet involvement; quarantine and treatment; buying practices; grazing livestock; animals re-entering the farm; pest control; visitors; equipment; and hygiene (Table 4). The measure rated most effective overall was measure 7 (maintain a closed herd), followed by 14 (prevent nose-to-nose contact with neighboring animals by maintaining adequate fencing),12 (test new animals bought onto the farm to assess their disease status), and 6 (implement rapid culling of persistently infected animals where appropriate for the disease). The most practical measure was measure 3 (maintain regular contact with the vet), followed by 16 (do not spread fields with imported slurry), 13 (avoid hiring bulls), and 2 [establish a herd health protocol (e.g., by using a herd health plan)].
Figure 1 shows a scatter plot presenting measures' effectiveness scores on the y-axis and the practicality scores on the x-axis. Scores were normalized so that the average practicality and effectiveness scores were 0 and the standard deviation was 1 . If the measure scored above average for practicality, then it appears to the right hand side of the y-axis. If it scored above average for effectiveness, then it appears above the x-axis. Measures in the upper right quadrant were above average for both effectiveness and practicality, and measures in the lower left quadrant were below average for both effectiveness and practicality. In total, 9 measures scored above average for both effectiveness and practicality.

Measures related to knowledge planning and veterinary involvement $(1,2,3$, and 30$)$ all scored above average for effectiveness and practicality. Measure 3 scored significantly higher for practicality than for effectiveness $(P=0.007)$. Measure 30 (vaccinate for diseases not already on the farm) scored slightly below average for effectiveness and below average for practicality. In terms of measures relating to quarantine and treatment, measures 5 and 6 (vaccinate to control diseases already on the farm and implement rapid culling of persistently infected animals, respectively) also scored above average for both practicality and effectiveness. 
Measure 4 (isolate sick animals and monitor their disease status) scored close to average for effectiveness and below average for practicality. Any measures related to isolating or quarantining animals $(4,11,18$, and 19) scored below average for practicality.

All 7 measures related to buying in livestock scored above average for effectiveness, except for measure 9 (consulting with the seller farmer before buying in animals). Several measures related to buying in livestock had significantly higher effectiveness than practicality scores: $7(P<0.001), 10(P<0.001), 11(P<0.001)$, $12(P<0.001)$. Measures 8 (consulting with the seller farmer's vet), 10 (viewing accredited test results), and 12 (testing new animals brought on to the farm) scored above average for practicality. Measure 13 (avoid hiring bulls) was rated as one of the most practical measures. Measure 14 (preventing nose-to-nose contact between neighboring animals by maintaining adequate fencing) had a significantly higher effectiveness score than practicality score $(P<0.001)$. Measure 16 (do not spread fields with imported slurry) had a significantly higher practicality score than effectiveness score $(P<0.001)$.
The rest of the measures - related to isolating animals re-entering the farm, pest control, visitors, equipment and hygiene - all scored below average for effectiveness, except for measure 18 (isolating young re-entering the farm after being housed elsewhere), which had a significantly higher effectiveness than practicality score $(P<0.001)$. Most also scored below or near average for practicality, except for measure 28 (maintain good hygiene on the farm), which scored above average.

Another useful way to divide the data was to explore measures that relate to minimizing or eliminating disease risk through direct contact between farm animals (direct measures) and measures that relate to indirect contact between animals, including fomites or higherlevel strategic measures, such as disease planning and monitoring (indirect measures). The scatter plot in Figure 2 divides the normalized data into direct and indirect measures. Direct measures scored higher than indirect measures for effectiveness, with only 2 direct measures scoring below average (measures 9 and 19) and 3 indirect measures scoring above average (measures 1,2 , and 3 ).

Table 4. Effectiveness and practicality scores for each measure

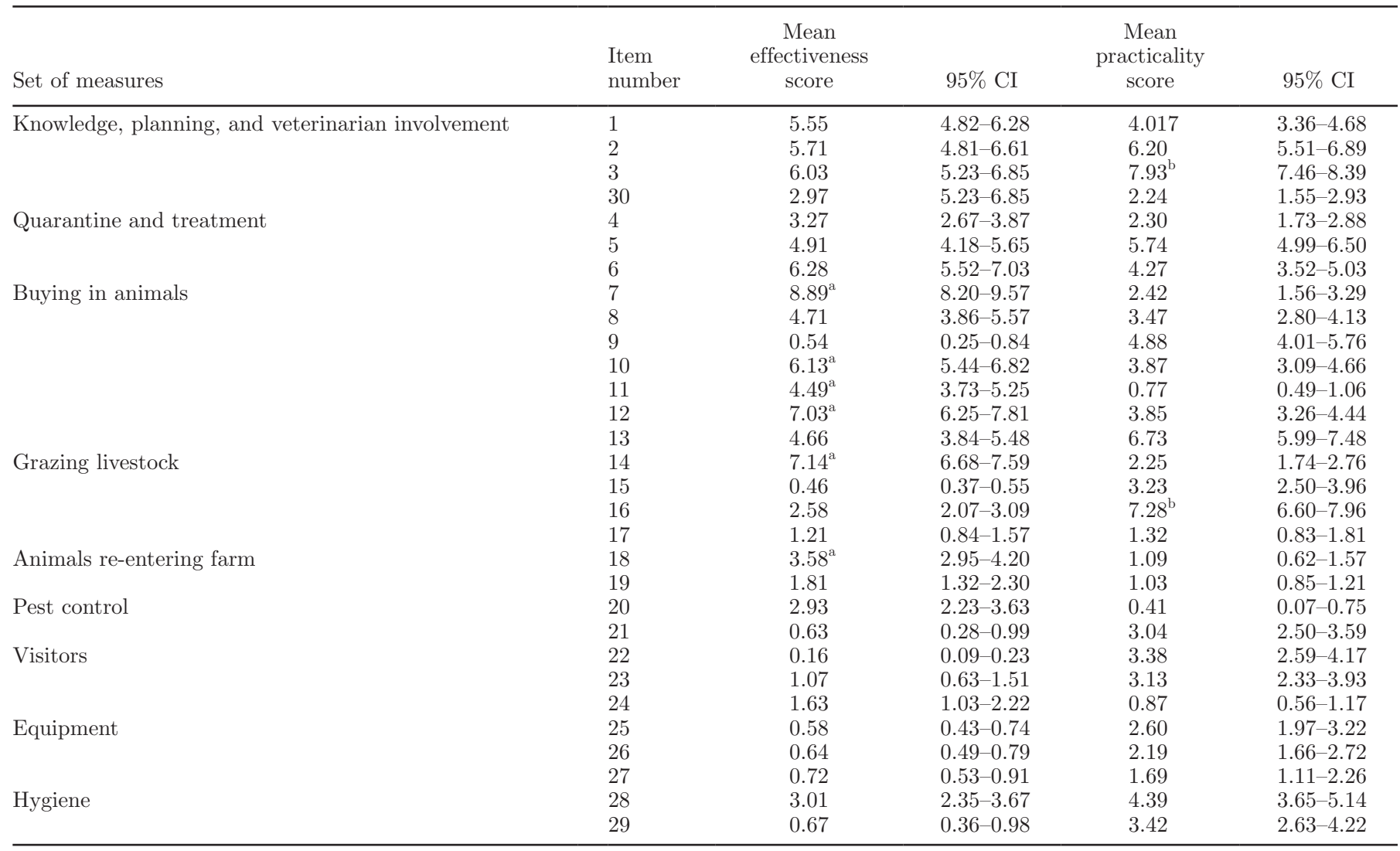

aThe measure's effectiveness score was significantly higher $(P \leq 0.05)$ than the practicality score.

${ }^{\text {b}}$ The measure's practicality score was significantly higher $(P \leq 0.05)$ than the effectiveness score. 
$\square$ Knowledge, planning and vet involvement

$\Delta$ Buying in animals

*Animals reentering the farm

$\Delta$ Quarantine and treatment

+ Visitors

$X$ Grazing livestock

O Pest control

国Hygiene

- Equipment

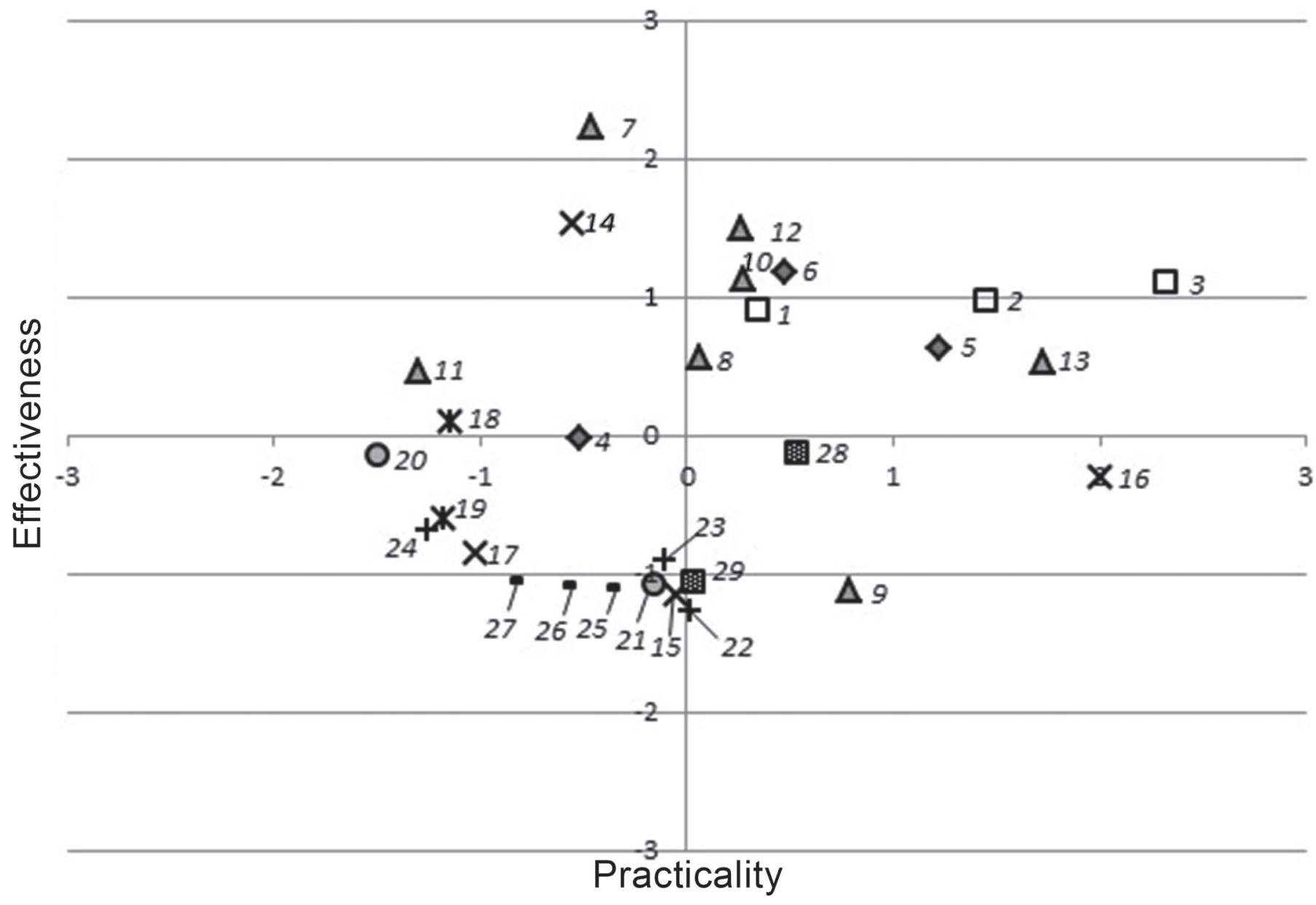

Figure 1. Zero-centered scatter plot of effectiveness and practicality scores by measure set. Practicality scores are on the x-axis, and effectiveness scores are on the y-axis. Refer to Table 1 for a list of biosecurity measures by number. Symbols in the legend indicate groups of measures.

\section{Choice Heterogeneity}

Thirteen measures showed some heterogeneity in effectiveness scores, with a coefficient of variation above 1 (Table 5). Of these, 7 had significant $(P<0.05)$ differences between respondent groups' scores. For instance, the vet respondent group rated measure 3 (maintain regular contact with your vet and discuss disease prevention and herd health status) as significantly more effective than the farmer respondent group $(P=0.002)$. Farmers rated measure 20 (prevent wildlife accessing housing sheds and food supplies) as significantly more effective than vets $(P=0.001)$. And vets rated measure
30 (implement a program of preventive vaccination for diseases not already on the farm) as significantly more effective than the farmer group $(P=0.013)$ and other group $(P<0.001)$. Nineteen measures showed some evidence of heterogeneity in practicality scores. Of these, 11 had significant differences among scores between respondent groups' scores. The vet group rated measure 5 (vaccinate to control diseases already on the farm) as significantly more practical than the farmer group $(P$ $=0.041$ ). The farmer group rated measure 7 (maintain a closed herd) as more practical than the vet group ( $P$ $=0.014)$ and other group $(P=0.006)$. Farmers also rated measure 14 (prevent nose-to-nose contact with 
neighboring animals by maintaining adequate fencing) as more practical than the vet group $(P<0.001)$ and the other group $(P=0.015)$.

\section{DISCUSSION}

This was the first study exploring the effectiveness and practicality of biosecurity measures implemented on dairy farms using choice modeling and the first study that included farmer choices in expert opinion for biosecurity.

One key finding of the study was that measures related to direct animal-to-animal contact were rated as clearly more effective than measures related to indirect contact. These were measures related to buying in new animals; reintroducing animals to the farm; and noseto-nose contact between animals on contiguous farms. This point is reiterated in the literature (Van Winden et al., 2005; Defra, 2006; Sibley, 2010; Cooke and Brownlow, 2011; Mee et al., 2012). The effectiveness of direct and indirect measures will depend on the epidemiology of the disease, because diseases that are highly infectious but fragile (such as bovine herpesvirus type 1) are more likely to be spread by direct contact, whereas pathogens that are more robust and can survive in the environment for longer (such as the foot and mouth disease virus and bovine tuberculosis virus) are more likely to be spread by indirect contact (Sibley, 2010). However, we observed a clear trend in the data showing the higher effectiveness of direct measures.

Of the direct measures, the high effectiveness scores of buying-in practices is supported in the literature (Maunsell and Donovan, 2008; Gorden and Plummer, 2010), and keeping a closed herd has also been cited or rated in reviews and expert studies as the most effective or important measure (Van Winden et al., 2005; Cooke and Brownlow, 2011; Mee et al., 2012; Sayers et al., 2014). However, maintaining a closed herd scored below average for practicality in the present study. Maintaining a completely closed herd is recognized as difficult for a farmer to achieve, and some maintain that it is likely to remain so in the future, because many dairy herds in Britain aim to expand production or need to replace animals culled because of diseases such as bovine tuberculosis (Sibley, 2010). It was interesting to note that farmers rated keeping a closed herd as significantly more practical than vets and others. This may have been because the farmers surveyed in this study were expert farmers who defined themselves (or were defined by research partners) as having an

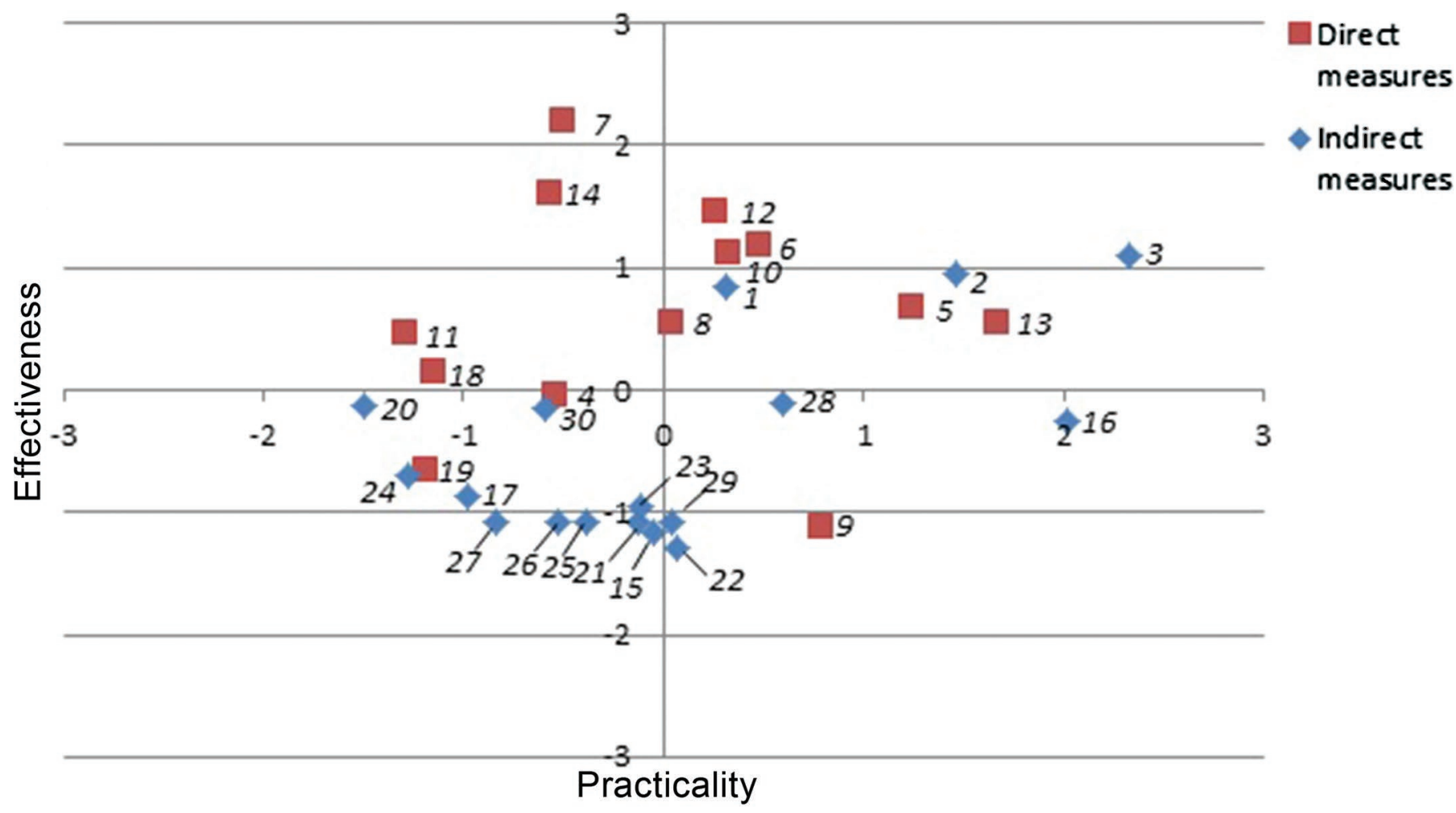

Figure 2. Zero-centered scatter plot of effectiveness and practicality scores as direct or indirect measures. Practicality scores are on the $\mathrm{x}$-axis, and effectiveness scores are on the y-axis. Refer to Table 1 for a list of biosecurity measures by number. Color version available online. 
Table 5. Heterogeneity within scores

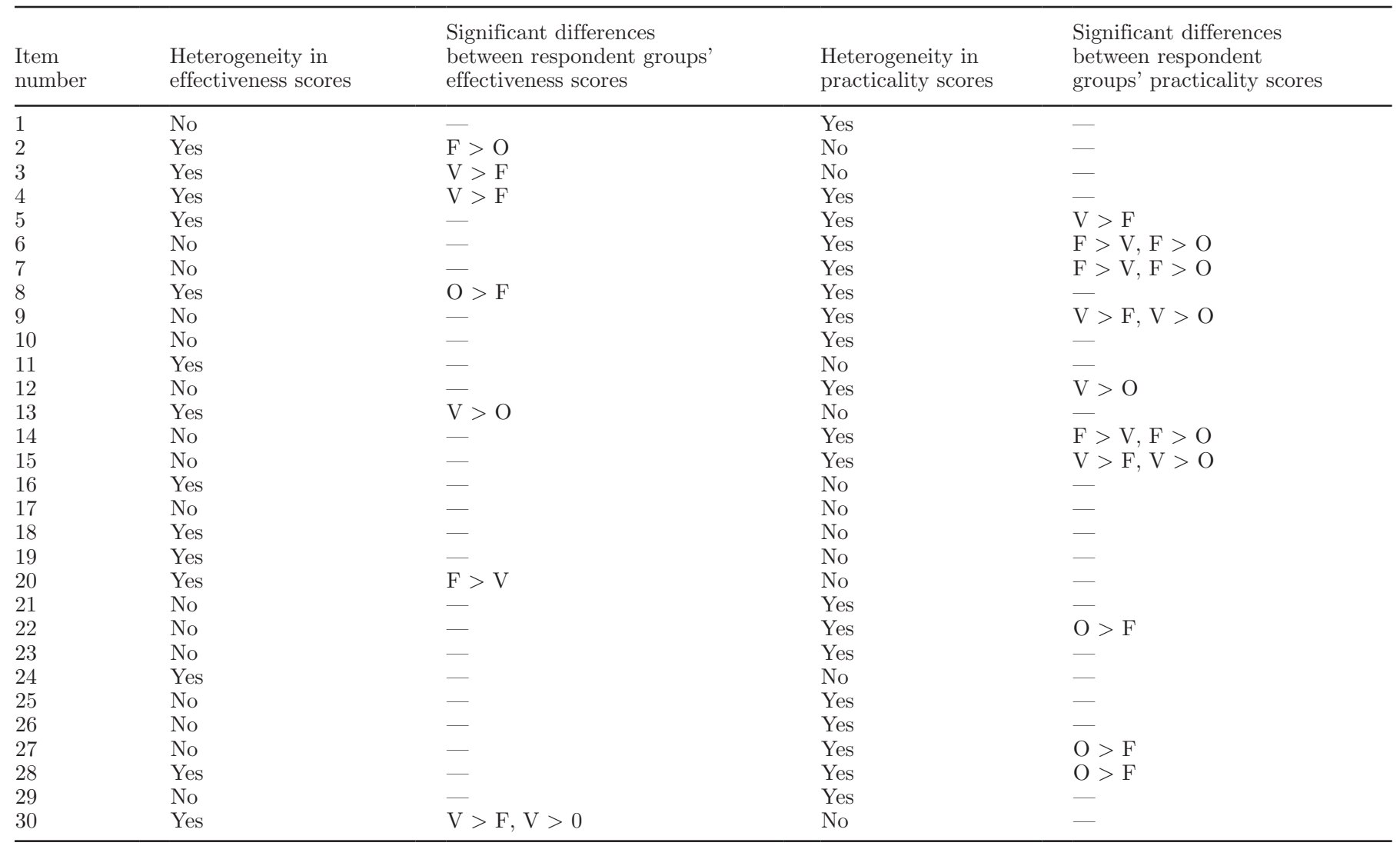

$\mathrm{F}=$ farmer respondent group, $\mathrm{O}=$ other respondent group, $\mathrm{V}=$ veterinarian respondent group. $\mathrm{F}>\mathrm{O}$ means that the farmer respondent group scored a measure as significantly $(P<0.05)$ more effective than the other respondent group, and likewise for veterinarian and other groups.

interest in biosecurity, and vets and others may have been answering the questions with average farmers in mind. It could also be that farmers, vets, and others were operating with a slightly different definition of a closed herd, because Sayers et al. (2014) found that some farmers claimed to have a closed herd but did buy in some animals.

The second most effective measure overall, measure 14 (preventing nose-to-nose contact between neighboring animals through maintaining adequate fencing) was also considered to be important in other expert studies (Van Winden et al., 2005; Sayers et al., 2014). Local disease spread, including through nose-to-nose contact, was considered especially important for dairy farms compared with cattle operations by Gates et al. (2013), because dairy farms tend to be relatively densely clustered in the United Kingdom. This measure also scored below average for practicality, and Sibley (2010) stated that adequate fencing can be expensive and difficult for individual farmers to maintain, suggesting that a regional approach involving cooperation between farmers may be more suitable for improving implementation.
The results of the present study suggested that isolating animals was considered an effective biosecurity measure, but was particularly difficult for dairy farmers to achieve, because all measures relating to isolating animals $(4,11,18$, and 19) scored below average for practicality. Studies have suggested that only a small proportion of farmers isolate purchased stock (Brennan and Christley, 2012; Gates et al., 2013). Farmers may not have adequate facilities for isolating animals, and it can be very labor- and time-intensive to manage isolated animals separately, especially in relation to milking, because this would require isolated animals to be milked separately, potentially disinfecting milking machines before and after use, and many farmers do not have the resources to achieve this (Sibley, 2010).

Measures 10 and 12 (buy animals with accredited test results and test new animals brought onto the farm to assess their disease status) scored highly for effectiveness, but their effectiveness can be limited by a lack of availability of accredited disease-free herds to purchase from (Sibley, 2010) and the poor sensitivity of some tests (Maunsell and Donovan, 2008). This real- 
ity seems to be reflected in the present study, because for both measures 10 and 12, practicality scores were significantly lower than effectiveness scores. Gates et al. (2013) suggested that testing and isolating boughtin animals were effective approaches, but that action needed to be taken based on the test results, such as exclusion of these animals from the herd, or treatment. How well a biosecurity measure is carried out will also have an effect on its effectiveness, because isolation measures can be more or less rigorous and complete (Gates et al., 2013).

The only one of the buying-in measures that scored below average for effectiveness was measure 9 (consulting the seller farmer about the animals' disease status), although vets and others groups rated it as more practical than the farmer group. This may have been because there is an asymmetry of information between the seller and buyer farmers; seller farmers may not be obliged to inform buyers about any disease problems (Mee et al., 2012), and a large proportion of farmers can be unaware of the disease status of their animals for a particular disease at a given time (Gates et al., 2013), meaning they may not be in a position to pass this information on to the buyer.

The biosecurity measures related to buying in animals were seen as some of the most effective, but also some of the least practical to implement. This added a further rationale to the literature that suggests that simply giving farmers more information will not improve biosecurity on farms (Jansen et al., 2010; Kristensen and Jakobsen, 2011). Farmers cannot implement measures that are very impractical for them. This study supports the need for recognition of this point in the wider debate, as well as a discussion of what individual farmers can and cannot control and where else change needs to come from (Enticott, 2008).

Measures relating to knowledge planning and veterinary involvement also scored highly for effectiveness (measures 1, 2, and 3, but not measure 30). This resonated with an extensive literature on the important role of the vet as gatekeeper and promoter of biosecurity (Cannas da Silva et al., 2006; Lowe, 2009; Orpin and Sibley, 2014; Statham and Green, 2015). Vets rated measure 3 (maintain regular contact with the vet) as significantly more effective than farmers did. It is perhaps not surprising that vets believed their services were valuable in helping to promote good biosecurity. However, the literature includes many suggestions that vets need to become better at promoting their services as disease-prevention and management consultants rather than their more traditional role of treating individual sick animals (Ruston et al., 2016). The difference we observed between vet and farmer scores could bear this out, if even expert farmers, who presumably have a good working relationship with a vet, rated the effectiveness of their services lower than vets did. Interestingly, maintaining regular contact with the vet was rated as the most practical measure overall, by both farmer and vet groups. This was interesting, given that several barriers to better implementation of biosecurity measures have been highlighted in the vet-farmer relationship, including lack of farmer and vet time, farmer's financial barriers, and a perception by vets that farmers are not interested in biosecurity (Gunn et al., 2008). This finding could be related to the familiarity of the farmer-vet relationship, meaning that vets can tailor biosecurity advice to farmers (Ruston et al., 2016).

It is perhaps surprising that measure 30 (vaccinating for disease not already on the farm) did not score more highly for effectiveness and practicality. Vets were the only group who rated this as above average for effectiveness, and they rated it more highly than farmers and others. Preventive vaccination is promoted as an important measure for many common livestock diseases (Wells, 2000; Mee et al., 2012; Paton, 2013), and vaccination is widely implemented by farmers in the United Kingdom: Cresswell et al. (2014) found that $86 \%$ of farmers they surveyed had vaccinated their cattle for at least 1 disease in the previous year. Measure number 5 (vaccinating for diseases already on the farm) scored higher for effectiveness and practicality, although vets gave it a significantly higher score for practicality than farmers. Compliance is lacking with vaccination protocols in terms of timing of doses, storage, and other factors that could affect the effectiveness of vaccinations (Cresswell et al., 2014), and veterinary advice around when and what to vaccinate for has also been shown to vary (Cresswell et al., 2013). These factors might explain the relatively low results for preventive vaccination, and why farmers see vaccination as less practical than vets do. However, more work could be done on why scores differed between vaccination as a preventive or a treatment measure, and between farmer and veterinary scores.

All indirect measures relating to pest control, visitors, equipment, and hygiene were rated below average for effectiveness and most were below average for practicality. Experts consulted in the studies by Sayers et al. (2014) and Van Winden et al. (2005) also rated the biosecurity risk of visitors as relatively low, and the risk from shared equipment as relatively low (Van Winden et al., 2005). Different types of visitors pose different levels of risk, and visitors who regularly visit other farms may pose a greater risk (Sibley, 2010).

Arguably, we need a greater recognition in debates about biosecurity that direct measures are perceived to be more effective than indirect measures. In a study of biosecurity recommendations across different livestock 
species, Moore et al. (2008) found that the most commonly recommended measures were indirect measures relating to equipment and visitors; operational policies, infrastructure, and animal identification were recommended less often. In an interview study with farm animal vets, Shortall et al. (2016) found that vets praised what they perceived as the superior biosecurity of the pig and poultry sectors over the dairy sector, partly because of the enclosed nature of these units, which allows for greater control over fomites. However, this study suggests that the control of fomites is not the most pressing biosecurity issue and advocating enclosed dairy units will not solve greater problems related to buying in animals.

Best-worst scaling was best suited to evaluating a large number of measures, which would have been too cognitively demanding for respondents to rank in a list. The model allowed us to calculate an overall mean with credible intervals and respondent-specific estimates of effectiveness and practicality, so that we could investigate degree of consensus or disagreement (i.e., choice heterogeneity), which is generally lacking in evaluation of expert opinion. We found evidence of heterogeneity among experts on the effectiveness and practicality of biosecurity measures, similar to the findings of Cross et al. (2012). Caution should be used when attempting to make inferences to the wider veterinary and farmer community, but because we chose a purposive sample of expert farmers and vets, our results suggest that the perceived effectiveness and practicality of certain biosecurity measures could differ significantly among vets and farmers and thus have implications for knowledge exchange. This variability in expert opinion could be because of lack of evidence on the efficacy and practicality of these measures or because of different experiences among groups; further work is needed to explore the sources of heterogeneity. The response rate was lowest among the farmer expert group (26\%). Low farmer response rates to surveys have been recognized as a problem among researchers, and is partly explained by survey fatigue, because farmers are approached to fill in a large number of surveys (Pennings et al., 2002). As with all expert opinion research that relies on nonprobability sampling, the expert elicitations in the study belong to the respondents who participated in the study and may not be representative of the overall population. However, we believe that by using strict and defined expert selection criteria, we have limited the potential bias. In this study, the biosecurity questions were not divided by type of farm or disease. The effectiveness of different biosecurity measures for different diseases can depend on many factors, including the transmission pathway of the disease, the time lag between exposure and acquiring the disease, whether or not the disease is zoonotic, how prevalent the disease is, how accurate tests for the disease are. The practicality of the measure can also vary according to many psychological and contextual factors on-farm (Enticott, 2008). However, we found a certain level of consistency in the responses within and between groups, such as the higher effectiveness of direct over indirect measures, and measures relating to buying in cattle. Others have also emphasized the potential for consistency across different biosecurity measures, in that one measure, such as keeping a closed herd, can be effective for several diseases (Defra, 2006; Carslake et al., 2011; Cooke and Brownlow, 2011).

The wording of the measures was by necessity open to interpretation. Measures could also be applied in different ways, with a potentially wide effect on effectiveness and practicality. As well, several measures and variations on measures were not included in the study (Maunsell and Donovan, 2008; Mee et al., 2012).

The results did not provide an absolute measure of the effective or practical a biosecurity measure is considered to be, providing instead a relative estimation of which measures were more or less practical or effective. To obtain an absolute assessment of effectiveness, studies such as randomized controlled trials are necessary.

This study was based in the United Kingdom, but the results can be applied to dairy sectors in other Western countries. The United Kingdom has the second largest average herd size in the European Union after Denmark and the mixed production system is typical, although countries such as Denmark and the Netherlands could be considered to have intensive systems, and countries such as Ireland to have more extensive systems (Promar International Limited, 2014). Dairy sectors in certain European countries, such as Scandinavian countries, have less endemic disease than the United Kingdom, thanks to successful eradication programs (Moennig et al., 2005). This would mean that they may make less use of vaccination as a control and prevention measure than the United Kingdom. In the United States, farms are on average much bigger than in the United Kingdom, and systems are more intensive, with cows spending more time indoors (Barkema et al., 2015). The effectiveness of measures could be seen to vary more based on the types of disease threats faced by a country's dairy sector, rather than the type of production system used. It has been suggested that dairy farms in the United States also need to improve the biosecurity of their buying practices (Wells, 2000; Barkema et al., 2015). The practicality of carrying out measures could vary more between countries based on the structure of their dairy sector and the facilities on dairy farms. Where industry and government initiatives are well established to minimize the disease risk from buying in 
animals (such as in Scandinavian countries), buying-in measures may be more practical for farmers to carry out. Minimizing contact with wildlife and neighboring animals could be more practical in systems where cows are housed for a greater part of the year, such as in the United States. Large farms may have more facilities for isolating cows, more disinfecting equipment, and more protocols for minimizing disease risks from visitors, making these measures more practical. However, these are areas even large farms in the United States need to work on (Barkema et al., 2015).

The results of the present study were disseminated and discussed in a consensus panel of vets and farmers and will be made available in a report prepared for the funding body Agriculture and Horticulture Development Board Dairy, which will also take steps to disseminate the results to farmers.

\section{CONCLUSIONS}

The present study gathered expert opinion from farmers, vets, consultants, academics, and government and industry representatives on the practicality and effectiveness of different biosecurity measures on dairy farms using best-worst scaling. The results showed that keeping a closed herd was rated as the most effective measure overall, and maintaining regular contact with the vet as the most practical. Measures relating to knowledge, planning, and veterinary involvement; buying-in practices; and quarantine and treatment scored highly overall for effectiveness. Measures relating to visitors, equipment, pest control, and hygiene scored relatively lower for effectiveness. Overall, measures relating to direct animal-to-animal contact scored much higher for effectiveness than measures relating to indirect disease transmission. Some of the most effective measures were also rated as the least practical, such as keeping a closed herd and avoiding nose-to-nose contact between contiguous animals.

\section{ACKNOWLEDGMENTS}

The authors acknowledge the Agriculture and Horticulture Development Board Dairy for funding this research as part of the project "Infectious disease control in dairy cows: Provision of practical guidance on biosecurity and vaccination strategies." The authors also acknowledge the University of Nottingham and the Centre for Evidence Based Veterinary Medicine for supporting this work. The authors thank members of the Herd Health group at the School of Veterinary Medicine and Science at the University of Nottingham for their help in developing and piloting the survey. The authors also thank the participants who gave up their time to take part in the study.

\section{REFERENCES}

Adamsen, J. M., S. Rundle-Thiele, and J. A. Whitty. 2013. Best-worst scaling . . Reflections on presentation, analysis, and lessons learnt from case 3 BWS experiments. Marketing Social Res. 21:1-54.

AHDB (Agriculture and Horticulture Development Board) Dairy. 2016. Dairy Statistics: An Insider's Guide 2016. AHDB, Kenilworth, UK.

Andersons Centre. 2013. The Structure of the GB Dairy Farming Industry - What Drives Change? AHDB Dairy, Kenilworth.

Barkema, H. W., M. G. von Keyserlingk, J. P. Kastelic, T. J. G. M. Lam, C. Luby, J.-P. Roy, S. J. LeBlanc, G. P. Keefe, and D. F. Kelton. 2015. Invited review: Changes in the dairy industry affecting dairy cattle health and welfare. J. Dairy Sci. 98:7426-7445. https://doi.org/10.3168/jds.2015-9377.

Bate, A. 2016. UK Dairy Industry Statistics. House of Commons Library, London, UK.

Bijker, W. E., R. Bal, and R. Hendriks. 2009. The Paradox of Scientific Authority: The Role of Scientific Advice in Democracies. MIT Press, Cambridge, MA.

Brennan, M. L., and R. M. Christley. 2012. Biosecurity on cattle farms: A study in north-west England. PLoS One 7:e28139 https://doi. org/10.1371/journal.pone.0028139.

Brennan, M. L., and R. M. Christley. 2013. Cattle producers' perceptions of biosecurity. BMC Vet. Res. 9:71 https://doi. org/10.1186/1746-6148-9-71.

Burgman, M., F. Fidler, M. McBride, T. Walshe, and B. Wintle. 2006. Eliciting Expert Judgments. Australian Centre of Excellence for Risk Analysis, Melbourne, Australia.

Cannas da Silva, J., J. P. T. M. Noordhuizen, M. Vagneur, R. Bexiga, C. C. Gelfert, and W. Baumgartner. 2006. Veterinary dairy herd health management in Europe: Constraints and perspectives. Vet. Q. 28:23-32. https://doi.org/10.1080/01652176.2006.9695203.

Carslake, D., W. Grant, L. E. Green, J. Cave, J. Greaves, M. Keeling, J. McEldowney, H. Weldegebriel, and G. F. Medley. 2011. Endemic cattle diseases: Comparative epidemiology and governance. Philos. Trans. R. Soc. Lond. B Biol. Sci. 366:1975-1986. https:// doi.org/10.1098/rstb.2010.0396.

Cohen, S., and B. Orme. 2004. What's your preference? Market Res. 16:32-37.

Cooke, R., and A. Brownlow. 2011. An integrated approach to biosecurity on UK cattle and sheep farms: Evaluating existing measures for endemic diseases against exotic threats. Appendix 1, Biosecurity review. Defra, London, UK.

Cresswell, E., M. L. Brennan, H. W. Barkema, and W. Wapenaar. 2014. A questionnaire-based survey on the uptake and use of cattle vaccines in the UK. Vet. Rec. Open. 1:e000042-e000042. https:// doi.org/10.1136/vropen-2014-000042.

Cresswell, L., I. Richens, S. Archer, J. Breen, J. Huxley, and L. Randall. 2013. Veterinary vaccination advice and perceived farmer compliance on UK dairy farms. Livestock 18:166-174.

Cross, P., D. Rigby, and G. Edwards-Jones. 2012. Eliciting expert opinion on the effectiveness and practicality of interventions in the farm and rural environment to reduce human exposure to Escherichia coli 0157. Epidemiol. Infect. 140:643-654. https://doi. org/10.1017/S0950268811001257.

Defra and Welsh Assembly Government. 2004. Animal Health and Welfare Strategy for Great Britain. Defra, London, UK.

Defra. 2003. Biosecurity Guidance to Prevent the Spread of Animal Diseases. Defra, London, UK.

Defra. 2006. Development of Farm-Specific Biosecurity Risk Management Strategies for Cattle Herds and Sheep Flocks. 5. Defra, Hatfield, UK.

Enticott, G. 2008. The spaces of biosecurity: Prescribing and negotiating solutions to bovine tuberculosis. Environ. Plann. A 40:15681582. https://doi.org/10.1068/a40304. 
Erdem, S., D. Rigby, and A. Wossink. 2012. Using best-worst scaling to explore perceptions of relative responsibility for ensuring food safety. Food Policy 37:661-670. https://doi.org/10.1016/j. foodp01.2012.07.010.

European Commission. 2013. Proposal for a Regulation of the European Parliament and of the Council on Animal Health. European Union, Brussels, Belgium.

Finn, A., and J. J. Louviere. 1992. Determining the appropriate response to evidence of public concern: The case of food safety. J. Public Policy Mark. 11:12-25. https://doi.org/10.2307/30000270.

Flynn, T. N., J. J. Louviere, T. J. Peters, and J. Coast. 2008. Estimating preferences for a dermatology consultation using Best-Worst Scaling: Comparison of various methods of analysis. BMC Med. Res. Methodol. 8:76 https://doi.org/10.1186/1471-2288-8-76.

Garabed, R. B., M. Perez, W. O. Johnson, and M. C. Thurmond 2009. Use of expert opinion for animal disease decisions: An example of foot-and-mouth disease status designation. Prev. Vet. Med. 92:20-30. https://doi.org/10.1016/j.prevetmed.2009.06.010.

Garforth, C. J., P. Bailey, and R. B. Tranter. 2013. Farmers' attitudes to disease risk management in England: A comparative analysis of sheep and pig farmers. Prev. Vet. Med. 110:456-466. https://doi. org/10.1016/j.prevetmed.2013.02.018.

Gates, M. C., M. E. J. Woolhouse, G. J. Gunn, and R. W. Humphry. 2013. Relative associations of cattle movements, local spread, and biosecurity with bovine viral diarrhoea virus (BVDV) seropositivity in beef and dairy herds. Prev. Vet. Med. 112:285-295. https:// doi.org/10.1016/j.prevetmed.2013.07.017.

Gorden, P. J., and P. Plummer. 2010. Control, management, and prevention of bovine respiratory disease in dairy calves and cows. Vet. Clin. North Am. Food Anim. Pract. 26:243-259. https://doi. org/10.1016/j.cvfa.2010.03.004.

Gunn, G. J., C. Heffernan, M. Hall, A. McLeod, and M. Hovi. 2008 Measuring and comparing constraints to improved biosecurity amongst GB farmers, veterinarians and the auxiliary industries. Prev. Vet. Med. 84:310-323. https://doi.org/10.1016/j. prevetmed.2007.12.003.

Hartzler, A., and W. Pratt. 2011. Managing the personal side of health: How patient expertise differs from the expertise of clinicians. J. Med. Internet Res. 13:1-18. https://doi.org/10.2196/jmir.1728

Horst, H.,, R. B. M. Huirne, and A. A. Dijkhuizen. 1996. Eliciting the relative importance of risk factors concerning contagious animal diseases using conjoint analysis: A preliminary survey report. Prev. Vet. Med. 27:183-195. https://doi.org/10.1016/01675877(95)01003-3.

Jansen, J., C. D. M. Steuten, R. J. Renes, N. Aarts, and T. J. G. M. Lam. 2010. Debunking the myth of the hard-to-reach farmer: Effective communication on udder health. J. Dairy Sci. 93:12961306. https://doi.org/10.3168/jds.2009-2794.

Jones, K., D. L. Jones, G. Edwards-Jones, and P. Cross. 2013. Informing decision making in agricultural greenhouse gas mitigation policy: A Best-Worst Scaling survey of expert and farmer opinion in the sheep industry. Environ. Sci. Policy 29:46-56. https://doi. org/10.1016/j.envsci.2013.02.003.

Kristensen, E., and E. B. Jakobsen. 2011. Challenging the myth of the irrational dairy farmer: Understanding decision-making related to herd health. N. Z. Vet. J. 59:1-7. https://doi.org/10.1080/004801 69.2011 .547162

Kuster, K., M.-E. Cousin, T. Jemmi, G. Schüpbach-Regula, and I. Magouras. 2015. Expert opinion on the perceived effectiveness and importance of on-farm biosecurity measures for cattle and swine farms in Switzerland. PLoS One 10:e0144533 https://doi. org/10.1371/journal.pone.0144533.

Kuster, K. B. 2013. Effectiveness and importance of on-farm biosecurity measures in Switzerland. Doctoral thesis. University of Bern.

Lancsar, E., and E. Savage. 2004. Deriving welfare measures from discrete choice experiments: Inconsistency between current methods and random utility and welfare theory. Health Econ. 13:901-907. https://doi.org/10.1002/hec.870.

Louviere, J., I. Lings, T. Islam, S. Gudergan, and T. Flynn. 2013. An introduction to the application of (case 1) best-worst scaling in marketing research. Int. J. Res. Mark. 30:292-303. https://doi org/10.1016/j.ijresmar.2012.10.002.

Lowe, P. 2009. Unlocking Potential: A Report on Veterinary Expertise in Food Animal Production. Vets and Veterinary Steering Group, London, UK.

Martin, T. G., M. A. Burgman, F. Fidler, P. M. Kuhnert, S. Low-Choy, M. McBride, and K. Mengersen. 2012. Eliciting expert knowledge in conservation science. Conserv. Biol. 26:29-38. https://doi org/10.1111/j.1523-1739.2011.01806.x.

Maunsell, F., and G. A. Donovan. 2008. Biosecurity and risk management for dairy replacements. Vet. Clin. North Am. Food Anim. Pract. 24:155-190. https://doi.org/10.1016/j.cvfa.2007.10.007.

Mcfadden, D. 1980. Econometric models for probabilistic choice among products. J. Bus. 53:S13-S29.

Mee, J. F., T. Geraghty, R. O'Neill, and S. J. More. 2012. Bioexclusion of diseases from dairy and beef farms: Risks of introducing infectious agents and risk reduction strategies. Vet. J. 194:143-150. https://doi.org/10.1016/j.tvj1.2012.07.001.

Moennig, V., H. Houe, and A. Lindberg. 2005. BVD control in Europe: Current status and perspectives. Anim. Health Res. Rev. 6:63-74. https://doi.org/10.1079/AHR2005102.

Moore, D. A., M. M. L. Merryman, M. L. Hartman, and D. J. Klingborg. 2008. Production animal species and classes. J. Am. Vet. Med. Assoc. 233:249-256.

Oliver, D. M., R. D. Fish, M. Winter, C. J. Hodgson, A. L. Heathwaite, and D. R. Chadwick. 2012. Valuing local knowledge as a source of expert data: Farmer engagement and the design of decision support systems. Environ. Model. Softw. 36:76-85.

Orpin, P., and D. Sibley. 2014. Predict and prevent versus test and treat. Vet. Rec. 174:403-405. https://doi.org/10.1136/vr.g2749.

Paterson, B., and S. Thorne. 2000. Developmental evolution of expertise in diabetes self-management. Clin. Nurs. Res. 9:402-419.

Paton, N. 2013. Cattle vaccination: Decision making in herd health planning. In Pract. 35:77-84. https://doi.org/10.1136/inp.f161.

Pearson, A., R. Wiechula, A. Court, and C. Lockwood. 2007. A re-consideration of what constitutes "evidence" in the healthcare professions. Nurs. Sci. Q. 20:85-88. https://doi. org $/ 10.1177 / 0894318406296306$.

Pennings, J. M. E., S. H. Irwin, and D. L. Good. 2002. Surveying farmers: A case study. Rev. Agric. Econ. 24:266-277. https://doi. org/10.1111/1467-9353.00096.

Petrie, A., and P. Watson. 2013. Statistics for Veterinary and Animal Science. Wiley-Blackwell, Oxford, UK.

Promar International Limited. 2014. The European Dairy Industry Towards 2020. Promar International Limited, London, UK.

RCVS. 2016. RCVS Certificate holders. RCVS, London, UK.

Ruston, A., O. Shortall, M. Green, M. Brennan, W. Wapenaar, and J. Kaler. 2016. Challenges facing the farm animal veterinary profession in England: A qualitative study of veterinarians' perceptions and responses. Prev. Vet. Med. https://doi. org/10.1016/j.prevetmed.2016.03.008.

Sawtooth Software. 2009a. CBC/HB for beginners. Research Paper Series 1-6. Sawtooth Software Inc., Sequim, WA.

Sawtooth Software. 2009b. Maxdiff analysis: Simple counting, individual level logit and HB. Sawtooth Software Inc., Sequim, WA.

Sawtooth Software. 2009c. The CBC system for choice-based conjoint analysis. Sawtooth Software Inc., Sequim, WA.

Sawtooth Software. 2009d. The CBC/HB System for Hierarchical Bayes Estimation Version 5.0. Technical Paper. Sawtooth Software Inc., Sequim, WA.

Sawtooth Software. 2014. Fit statistics calculation. Sawtooth Software Inc., Sequim, WA.

Sayers, R. G., M. Good, and G. P. Sayers. 2014. A survey of biosecurity-related practices, opinions and communications across dairy farm veterinarians and advisors. Vet. J. 200:261-269. https://doi. org $/ 10.1016 / j . t v j 1.2014 .02 .010$

Shortall, O., A. Ruston, M. Green, M. Brennan, W. Wapenaar, and J. Kaler. 2016. Broken biosecurity? Veterinarians' framing of biosecurity on dairy farms in England. Prev. Vet. Med. 132:20-31. https://doi.org/j.prevetmed.2016.06.001. 
Sibley, R. 2010. Biosecurity in the dairy herd. In Pract. 32:274-280. https://doi.org/10.1136/inp.c3913.

Slottje, P., J. P. van der Sluijs, and A. B. Knol. 2008. Expert Elicitation: Methodological Suggestions for Its Use in Environmental Health Impact Assessments. National Institute for Public Health and the Environment, Bilthoven, the Netherlands.

Sørensen, J. T., S. Østergaard, H. Houe, and J. Hindhede. 2002. Expert opinions of strategies for milk fever control. Prev. Vet. Med. 55:69-78. https://doi.org/10.1016/S0167-5877(02)00068-5.

Statham, J., and M. Green. 2015. Cattle veterinary services in a changing world. Vet. Rec. 176:276-280.

Thurstone, L. L. 1927. A law of comparative judgment. Psychol. Rev. 34:273-286. https://doi.org/10.1037/h0070288.

Valeeva, N.I., M. A. van Asseldonk, and G. B. Backus. 2011. Perceived risk and strategy efficacy as motivators of risk management strategy adoption to prevent animal diseases in pig farming. Prev. Vet. Med. 102:284-295. https://doi.org/10.1016/j.prevetmed.2011.08.005.

Valeeva, N. I., M. P. M. Meuwissen, R. H. M. Bergevoet, A. G. J. M. Oude Lansink, and R. B. M. Huirne. 2005. Improving food safety at the dairy farm level: Farmers' and experts' perceptions. Rev. Agric. Econ. 27:574-592. https://doi.org/10.1111/j.14679353.2005.00265.x.

Van Winden, S., K. Stevens, J. Guitian, and M. Mcgowan. 2005. Preliminary findings of a systematic review and expert opinion workshop on biosecurity on cattle farms in the UK. Cattle Pract. 13:135-140.

Voas, S. 2012. Working together to eradicate BVD in Scotland. Vet. Rec. 170:278-279. https://doi.org/10.1136/vr.e1777.

Wells, S. J. 2000. Biosecurity on dairy operations: Hazards and risks. J. Dairy Sci. 83:2380-2386. https://doi.org/10.3168/jds.S00220302(00)75127-7.

Whitty, J. A., R. Walker, X. Golenko, and J. Ratcliffe. 2014. A think aloud study comparing the validity and acceptability of discrete choice and best worst scaling methods. PLoS One 9:e90635 https://doi.org/10.1371/journal.pone.0090635. 